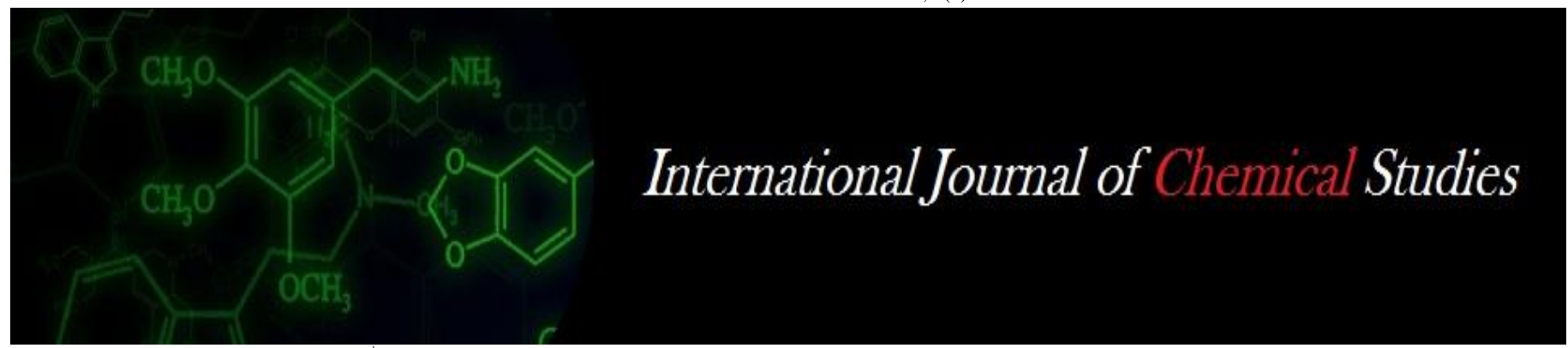

P-ISSN: 2349-8528

E-ISSN: 2321-4902

IJCS 2020; 8(1): 337-342

(C) 2020 IJCS

Received: 01-11-2019

Accepted: 05-12-2019

\section{Sanjekar MB}

Vasantrao Nai Marathwada Agricultural University,

Parbhani, Maharashtra, India

Nalwandikar PK

Vasantrao Nai Marathwada

Agricultural University,

Parbhani, Maharashtra, India

Bhamare VK

Vasantrao Nai Marathwada

Agricultural University,

Parbhani, Maharashtra, India

Corresponding Author:

Sanjekar MB

Vasantrao Nai Marathwada

Agricultural University,

Parbhani, Maharashtra, India

\section{Biometric studies of Corcyra cephalonica (Stainton) at different temperature levels}

\author{
Sanjekar MB, Nalwandikar PK and Bhamare VK
}

\begin{abstract}
The observed progression factors for larval head capsule width, body length, body width and body weight at $20{ }^{\circ} \mathrm{C}$ temperature were $1.05,1.25,0.97$, and 1.32 , respectively. The corresponding values at 25 ${ }^{0} \mathrm{C}, 30{ }^{\circ} \mathrm{C}$ and $35{ }^{\circ} \mathrm{C}$ temperature were $(1.16,1.40,0.99$ and 1.38$),(1.23,1.38,0.99$, and 1.37) and (1.16, $1.25,0.99$ and 1.48), respectively.
\end{abstract}

Keywords: Biometrics, Corcyra cephalonica (Stainton), temperature levels

\section{Introduction}

The rice moth, Corcyra cephalonica (Stainton) is able to survive in a wide range of temperature and humidity in fact the life cycle can be completed between $15^{\circ} \mathrm{C}$ and $35^{\circ} \mathrm{C}$ and between 15 to $90 \%$ relative humidity, and high damage has been reported even under extreme condition (Parameshwar \& Jairao, 1985) ${ }^{[4]}$ this characteristics are important element for explaining the ubiquitous distribution of Corcyra cephalonica which was comes in prominence in India in recent years mainly due to its adaptability for use as laboratory host of many parasitoids and predators employed in biological control of insect pests. There is little information available on the development of $C$. cephalonica under different sets of controlled temperatures and humidity on stored broken grains of sorghum mass multiplication of natural enemies depends on effective rearing of laboratory host like $C$. cephalonica under different environmental conditions (Parameshwar and Jairao, 1990) ${ }^{[4]}$.

\section{Material and Methods}

The laboratory experiments were conducted at the Department of Entomology, College of Agriculture, Latur during 2015-2016.

\section{Rearing of test insect}

The laboratory culture of rice moth Corcyra cephalonica Stainton (Pyralidae: Lepidoptera) was initiated by collecting larvae from previous culture of bio-control laboratory, Department of Entomology, during 2015. The larvae were reared individually in round clean plastic boxes. They were fed on crushed sorghum grains till pupation. After pupation the sexes of pupae were determined on the basis of distance between the two apertures. In case of male, the distance between genital and anal aperture is less, while it is more in case of female (Shrivastava and Pande, 1966 and Dani et al.1980) ${ }^{[6,2]}$. The adults that emerged on the same day were placed in oviposition cage for the purpose of egg laying and cotton swab dipped in 50 per cent honey solution was provided as food to the adults. Thus, the freshly laid eggs were used for investigation on biology, biometrics and life-fecundity of $C$. cephalonica at different temperature levels.

\section{Biometrical studies of $C$. cephalonica at different temperature levels}

The studies on biometrics of $C$. cephalonica were also carried out at four different temperature levels viz., $20{ }^{\circ} \mathrm{C}, 25{ }^{\circ} \mathrm{C}, 30{ }^{\circ} \mathrm{C}$ and $35{ }^{\circ} \mathrm{C}$. Immediately after hatching larvae of $C$. cephalonica for each instar were transferred into separate small plastic vials. They were reared individually at four different temperature levels viz., $20{ }^{\circ} \mathrm{C}, 25{ }^{\circ} \mathrm{C}, 30{ }^{\circ} \mathrm{C}$ and $35^{\circ} \mathrm{C}$. Every day fresh crushed sorghum grains were provided to the larvae. The observations on the casting of exuviae were made under microscope. During each instar immediately after moulting, the head capsule width and body length, width and weight of each larva was measured with the help of ocular 
and stage micrometer to the nearest value of $0.0091 \mathrm{~mm}$. The regression relationship between the instar and mean head capsule width, body length, body width and body weight of larvae in different instars was calculated by using the following formula.

$$
\log 10 Y=a+b x
$$

\section{Where}

$\mathrm{Y}=$ Head capsule width / body length / body width /body weight of larva (mean)

$\mathrm{a}=$ Constant

$\mathrm{b}=$ Logarithm of growth ratio $\mathrm{x}=$ Number of instars

\section{Result and Discussion \\ 1. Larval head capsule width \\ Temperature at $20^{\circ} \mathrm{C}$}

The results presented in Table 1 revealed that the larvae of $C$. cephalonica passed through six instars. The head capsule width was $0.82+0.01,1.12+0.01,1.42+0.01,2.96+0.01$, $3.68+0.01$ and $4.86+0.01 \mathrm{~mm}$ for I, II, II, IV, V and VI instars, respectively grown at $20{ }^{\circ} \mathrm{C}$ temperature. The mean observed and calculated progression factors were 1.05 and 1.09 , respectively. The regression equation was $\log _{10} \mathrm{y}=-$ $0.0861+0.1122 \mathrm{x}$

Table 1: Comparison of observed and calculated values of mean measurements of larval head capsule width (mm) of C. cephalonica on at $20^{\circ} \mathrm{C}$ temperatures

\begin{tabular}{|c|c|c|c|c|c|c|c|}
\hline \multirow{2}{*}{ Parameter } & \multicolumn{6}{|c|}{ Larval instars } & \multirow{2}{*}{$\begin{array}{c}\text { Progression } \\
\text { factor }\end{array}$} \\
\hline & I & II & III & IV & $\mathbf{V}$ & VI & \\
\hline Observed head capsule width $(\mathrm{mm})+$ S.E. & $0.82 \pm 0.01$ & $1.12 \pm 0.01$ & $1.42 \pm 0.01$ & $2.96 \pm 0.01$ & $3.68 \pm 0.01$ & $4.86 \pm 0.01$ & \\
\hline Growth ratio & -- & 1.37 & 1.27 & 1.08 & 1.24 & 1.32 & 1.05 \\
\hline Calculated head capsule width (mm) & 1.06 & 1.37 & 1.78 & 2.30 & 2.98 & 3.86 & \\
\hline Growth ratio & -- & 1.29 & 1.30 & 1.31 & 1.30 & 1.31 & 1.09 \\
\hline Difference & -0.24 & -0.25 & -0.36 & 0.65 & 0.69 & 0.99 & \\
\hline Per cent difference & 29.26 & 22.32 & 25.35 & 21.95 & 18.75 & 20.37 & \\
\hline
\end{tabular}

\section{Temperature at $25^{\circ} \mathrm{C}$}

C. cephalonica passed through six instars (Table 2) when reared at $25{ }^{0} \mathrm{C}$ temperature. The head capsule width was $0.98+0.01,1.3+0.01,1.4+0.01,2.1+0.01,3.5+0.01$ and
$4.95+0.01 \mathrm{~mm}$ for I, II, II, IV, V and VI instars, respectively. The mean observed and calculated progression factors were 1.16 and 1.06, respectively. The regression equation was $\log _{10} \mathrm{y}=-0.0633+0.1044 \mathrm{x}$

Table 2: Comparison of observed and calculated values of mean measurements of larval head capsule width (mm) of C. cephalonica at $25{ }^{\circ} \mathrm{C}$ temperature

\begin{tabular}{|c|c|c|c|c|c|c|c|}
\hline \multirow{2}{*}{ Parameter } & \multicolumn{6}{|c|}{ Larval instars } & \multirow{2}{*}{ Progression factor } \\
\hline & I & II & III & IV & $\mathbf{V}$ & VI & \\
\hline Observed head capsule width $(\mathrm{mm})+$ S.E & $0.98+0.01$ & $1.3+0.01$ & $1.4+0.01$ & $2.1+0.01$ & $3.5+0.01$ & $4.95+0.01$ & \\
\hline Growth ratio & -- & 1.33 & 1.08 & 1.50 & 1.67 & 1.41 & 1.16 \\
\hline Calculated head capsule width (mm) & 1.10 & 1.40 & 1.78 & 2.26 & 2.87 & 3.66 & \\
\hline Growth ratio & -- & 1.27 & 1.27 & 1.27 & 1.27 & 1.27 & 1.06 \\
\hline Difference & -0.12 & -0.10 & -0.38 & -0.16 & 0.63 & 1.29 & \\
\hline Per cent difference & -12.16 & -7.52 & -26.97 & -7.65 & 17.86 & 26.14 & \\
\hline
\end{tabular}

\section{Temperature at $30{ }^{\circ} \mathrm{C}$}

The results presented in Table 3 revealed that the larvae of $C$. cephalonica reared at $30{ }^{\circ} \mathrm{C}$ temperature passed through six instars. The larval head capsule width was $0.76+0.01,1.15+$ $0.01,2.26+0.01,3.16+0.01,4.15+0.01 \mathrm{~mm}$ and $5.01+$
$0.01 \mathrm{~mm}$ for I, II, III, IV, V and VI instars, respectively. The mean observed and calculated progression factors were 1.23 and 1.11 respectively. The regression equation was $\log _{10} \mathrm{y}=-$ $0.0771+0.1227 x$

Table 3: Comparison of observed and calculated values of mean measurements of larval head capsule width (mm) of C. cephalonica at $30^{\circ} \mathrm{C}$ temperature

\begin{tabular}{|c|c|c|c|c|c|c|c|}
\hline \multirow{2}{*}{ Parameter } & \multicolumn{4}{|c|}{ Larval instars } & \multirow{2}{*}{ Progression factor } \\
\cline { 2 - 8 } & I & II & III & IV & V & VI & \\
\hline Observed head capsule width $(\mathrm{mm})+$ S.E. & $0.76+0.01$ & $1.15+0.01$ & $2.26+0.01$ & $3.16+0.01$ & $4.15+0.01$ & $5.01+0.01$ & \\
\hline Growth ratio & -- & 1.51 & 1.97 & 1.40 & 1.31 & 1.21 & 1.23 \\
\hline Calculated head capsule width $(\mathrm{mm})$ & 1.11 & 1.47 & 1.95 & 2.59 & 3.44 & 4.56 & \\
\hline Growth ratio & -- & 1.33 & 1.33 & 1.33 & 1.33 & 1.33 & \\
\hline Difference & -0.35 & -0.32 & 0.31 & 0.57 & 0.71 & 0.45 & \\
\hline Per cent difference & -46.13 & -28.06 & 13.55 & 17.99 & 17.61 & 9.00 & \\
\hline
\end{tabular}

\section{Temperature at $35{ }^{\circ} \mathrm{C}$}

The results presented in Table 4 revealed that the larvae of $C$. cephalonica passed through six instars. The head capsule width was $0.98+0.01,1.54+0.01,2.14+0.01,2.97+$ $0.01,4.13+0.01$ and $4.99+0.01 \mathrm{~mm}$ for I, II, II, IV, V and VI instars, respectively when grown at $35{ }^{\circ} \mathrm{C}$ temperature. The mean observed and calculated progression factors were 1.16 and 1.10 , respectively. The regression equation was $\log _{10} \mathrm{y}=-$ $0.0258+0.1191 x$ 
Table 4: Comparison of observed and calculated values of mean measurements of larval head capsule width (mm) of C. cephalonica at $35{ }^{\circ} \mathrm{C}$ temperature

\begin{tabular}{|c|c|c|c|c|c|c|c|}
\hline \multirow{2}{*}{ Parameter } & \multicolumn{9}{|c|}{ Larval instars } & \multirow{2}{*}{ Progression factor } \\
\cline { 2 - 8 } & I & II & III & IV & V & VI & \\
\hline Observed head capsule width (mm) + S.E. & $0.98 \pm 0.01$ & $1.54 \pm 0.01$ & $2.14 \pm 0.01$ & $2.97 \pm 0.01$ & $4.13 \pm 0.01$ & $4.99 \pm 0.01$ & \\
\hline Growth ratio & -- & 1.57 & 1.39 & 1.39 & 1.39 & 1.21 & 1.16 \\
\hline Calculated head capsule width (mm) & 1.21 & 1.60 & 2.10 & 2.77 & 3.65 & 4.81 & \\
\hline Growth ratio & -- & 1.32 & 1.32 & 1.32 & 1.32 & 1.32 & 1.10 \\
\hline Difference & -0.14 & -0.09 & -0.01 & 0.15 & 0.42 & 0.11 & \\
\hline Per cent difference & -12.69 & -5.89 & -0.24 & 4.98 & 10.11 & 2.12 & \\
\hline
\end{tabular}

\section{Larval body length}

Temperature at $20^{\circ} \mathrm{C}$

The results presented in Table 5 indicated that the larval body length of $C$. cephalonica for I, II, II, IV, V and VI instars reared at $20{ }^{\circ} \mathrm{C}$ temperature was $1.75+0.02,4.11+0.04,6.01+$
$0.06,7.55+0.07,9.20+0.08$ and $11.00+0.10 \mathrm{~mm}$, respectively. The mean observed and calculated progression factors were 1.25 and 1.30. The regression equation was $\log _{10} \mathrm{y}=0.0771+0.1931 \mathrm{x}$.

Table 5: Comparison of observed and calculated values of mean measurements of larval body length (mm) of C. cephalonica at $20{ }^{\circ} \mathrm{C}$ temperature

\begin{tabular}{|c|c|c|c|c|c|c|c|}
\hline \multirow{2}{*}{ Parameter } & \multicolumn{9}{|c|}{ Larval instars } & \multirow{2}{*}{ Progression factor } \\
\cline { 2 - 8 } & I & II & III & IV & V & VI & \\
\hline Observed body length $(\mathrm{mm})+$ S.E. & $1.75 \pm 0.02$ & $4.11 \pm 0.04$ & $6.01 \pm 0.06$ & $7.55 \pm 0.07$ & $9.20 \pm 0.08$ & $11.00 \pm 0.10$ & \\
\hline Growth ratio & -- & 2.35 & 1.46 & 1.26 & 1.22 & 1.20 & 1.25 \\
\hline Calculated body length (mm) & 1.86 & 2.91 & 4.53 & 7.07 & 11.04 & 17.22 & \\
\hline Growth ratio & -- & 1.56 & 1.56 & 1.56 & 1.56 & 1.56 & 1.30 \\
\hline Difference & -0.11 & 1.20 & 1.48 & 0.48 & -1.84 & -6.22 & \\
\hline Per cent difference & -6.47 & 29.27 & 24.54 & 6.29 & -19.97 & -56.54 & \\
\hline
\end{tabular}

\section{Temperature at $25^{\circ} \mathrm{C}$}

The results presented in Table 6 indicated that the mean larval body length of $C$. cephalonica for I, II, II, IV, V and VI instars reared at $25{ }^{0} \mathrm{C}$ temperature was $1.28+0.02,4.22+$
$0.04,6.28+0.06,7.65+0.07,9.80+0.08$ and $11.21+0.10$ $\mathrm{mm}$, respectively. The mean observed and calculated progression factors were 1.40 and 1.31 , respectively. The regression equation was $\log _{10} \mathrm{y}=0.0493+0.1980 \mathrm{x}$.

Table 6: Comparison of observed and calculated values of mean measurements of larval body length (mm) of C. cephalonica at $25{ }^{\circ} \mathrm{C}$ temperature

\begin{tabular}{|c|c|c|c|c|c|c|c|}
\hline \multirow{2}{*}{ Parameter } & \multicolumn{9}{|c|}{ Larval instars } & \multirow{2}{*}{ Progression factor } \\
\cline { 2 - 8 } & I & II & III & IV & V & VI & \\
\hline Observed body length (mm) + S.E. & $1.28 \pm 0.02$ & $4.22 \pm 0.04$ & $6.28 \pm 0.06$ & $7.65 \pm 0.07$ & $9.80 \pm 0.8$ & $11.21 \pm 0.10$ & \\
\hline Growth ratio & -- & 3.30 & 1.49 & 1.22 & 1.28 & 1.14 & 1.40 \\
\hline Calculated body length (mm) & 1.77 & 2.79 & 4.40 & 6.94 & 10.95 & 17.28 & \\
\hline Growth ratio & -- & 1.58 & 1.58 & 1.58 & 1.58 & 1.58 & 1.31 \\
\hline Difference & -0.49 & 1.43 & 1.88 & 0.71 & -1.15 & -6.07 & \\
\hline Per cent difference & -38.09 & 33.91 & 29.93 & 9.25 & -11.77 & -54.17 & \\
\hline
\end{tabular}

\section{Temperature at $30{ }^{\circ} \mathrm{C}$}

The results presented in Table 7 indicated that the larval body length of $C$. cephalonica for I, II, II, IV, V and VI instars reared at $30{ }^{\circ} \mathrm{C}$ temperature was $1.32+0.02,4.11+0.04,6.51+$
$0.06,7.81+0.07,9.62+0.08$ and $11.35+0.10 \mathrm{~mm}$, respectively. The mean observed and calculated progression factors were 1.38 and 1.32 , respectively. The regression equation was $\log _{10} \mathrm{y}=0.0518+0.1985 \mathrm{x}$.

Table 7: Comparison of observed and calculated values of mean measurements of larval body length (mm) of C. cephalonica at $30{ }^{\circ} \mathrm{C}$ temperature

\begin{tabular}{|c|c|c|c|c|c|c|c|}
\hline \multirow{2}{*}{ Parameter } & \multicolumn{9}{|c|}{ Larval instars } & \multirow{2}{*}{ Progression factor } \\
\cline { 2 - 8 } & I & II & III & IV & V & VI & \\
\hline Observed body length (mm)+ S.E. & $1.32 \pm 0.02$ & $4.11 \pm 0.04$ & $6.51 \pm 0.06$ & $7.81 \pm 0.07$ & $9.62 \pm 0.08$ & $11.35 \pm 0.10$ & \\
\hline Growth ratio & -- & 3.11 & 1.58 & 1.20 & 1.23 & 1.18 & 1.38 \\
\hline Calculated body length (mm) & 1.78 & 2.81 & 4.44 & 7.01 & 11.07 & 17.49 & \\
\hline Growth ratio & -- & 1.58 & 1.58 & 1.58 & 1.58 & 1.58 & 1.32 \\
\hline Difference & -0.46 & 1.30 & 2.07 & 0.80 & -1.45 & -6.14 & \\
\hline Per cent difference & -34.80 & 31.62 & 31.82 & 10.25 & -15.08 & -54.05 & \\
\hline
\end{tabular}

\section{Temperature at $35{ }^{\circ} \mathrm{C}$}

The results presented in Table 8 indicated that the larval body length of $C$. cephalonica for I, II, II, IV, V and VI instars reared at $25{ }^{\circ} \mathrm{C}$ temperature was $1.56+0.02,3.22+0.04,5.22+$
$0.06,6.22+0.07,9.45+0.08$ and $10.22+0.10 \mathrm{~mm}$, respectively. The mean observed and calculated progression factors were 1.25 and 1.28 , respectively. The regression equation was $\log _{10} \mathrm{y}=0.0463+0.1866 \mathrm{x}$. 
Table 8: Comparison of observed and calculated values of mean measurements of larval body length (mm) of C. cephalonica on at $35{ }^{\circ} \mathrm{C}$ temperature

\begin{tabular}{|c|c|c|c|c|c|c|c|}
\hline \multirow{2}{*}{ Parameter } & \multicolumn{9}{|c|}{ Larval instars } & \multirow{2}{*}{ Progression factor } \\
\cline { 2 - 8 } & I & II & III & IV & V & VI & \\
\hline Observed body length (mm) + S.E. & $1.56 \pm 0.02$ & $3.22 \pm 0.04$ & $5.22 \pm 0.06$ & $6.22 \pm 0.07$ & $9.45 \pm 0.08$ & $10.22 \pm 0.10$ & \\
\hline Growth ratio & -- & 2.06 & 1.62 & 1.19 & 1.52 & 1.08 & 1.25 \\
\hline Calculated body length (mm) & 1.71 & 2.63 & 4.04 & 6.21 & 9.54 & 14.66 & \\
\hline Growth ratio & -- & 1.54 & 1.54 & 1.54 & 1.54 & 1.54 & \\
\hline Difference & -0.15 & 0.59 & 1.18 & 0.01 & -0.09 & -4.44 & \\
\hline Per cent difference & -9.60 & 18.39 & 22.63 & 0.21 & -0.95 & -43.46 & \\
\hline
\end{tabular}

\section{Larval body width}

Temperature at $20{ }^{\circ} \mathrm{C}$

The results presented in Table 9 indicated that the larval body width of $C$. cephalonica for I, II, II, IV, V and VI instars reared at $20^{\circ} \mathrm{C}$ temperature was $0.74+0.02,0.81+0.03,0.95+$
$0.04,1.15+0.05,1.35+0.06$ and $1.59+0.07 \mathrm{~mm}$, respectively. The mean observed and calculated progression factors were 0.97 and 0.89 , respectively. The regression equation was $\log _{10} \mathrm{y}=-0.0698+0.0270 \mathrm{x}$.

Table 9: Comparison of observed and calculated values of mean measurements of larval body width (mm) of C. cephalonica at $20{ }^{\circ} \mathrm{C}$ temperature

\begin{tabular}{|c|c|c|c|c|c|c|c|}
\hline \multirow{2}{*}{ Parameter } & \multicolumn{9}{|c|}{ Larval instars } & \multirow{2}{*}{ Progression factor } \\
\cline { 2 - 8 } & I & II & III & IV & V & VI & \\
\hline Observed larval body width (mm) + S.E. & $0.74 \pm 0.02$ & $0.81 \pm 0.03$ & $0.95 \pm 0.04$ & $1.15 \pm 0.05$ & $1.35 \pm 0.06$ & $1.59 \pm 0.07$ & \\
\hline Growth ratio & -- & 1.09 & 1.17 & 1.21 & 1.17 & 1.18 & 0.97 \\
\hline Calculated larval body width (mm) & 0.91 & 0.96 & 1.03 & 1.09 & 1.16 & 1.24 & \\
\hline Growth ratio & -- & 1.06 & 1.06 & 1.06 & 1.06 & 1.06 & \\
\hline Difference & -0.17 & -0.15 & -0.08 & 0.06 & 0.19 & 0.35 & \\
\hline Per cent difference & -22.45 & -19.04 & -8.00 & 5.06 & 13.95 & 22.25 & \\
\end{tabular}

\section{Temperature at $25{ }^{\circ} \mathrm{C}$}

The results presented in Table 10 indicated that the larval body width of $C$. cephalonica for I, II, II, IV, V and VI instars reared at $25{ }^{\circ} \mathrm{C}$ temperature was $0.69+0.02,0.85+0.03,0.91+$
$0.04,1.18+0.05,1.38+0.06$ and $1.65+0.07 \mathrm{~mm}$, respectively. The mean observed and calculated progression factors were 0.99 and 0.89 , respectively. The regression equation was $\log _{10} \mathrm{y}=0.0767+0.0294 \mathrm{x}$.

Table 10: Comparison of observed and calculated values of mean measurements of larval body width (mm) of C. cephalonica at $25^{\circ} \mathrm{C}$ temperature

\begin{tabular}{|c|c|c|c|c|c|c|c|}
\hline \multirow{2}{*}{ Parameter } & \multicolumn{4}{|c|}{ Larval instars } & \multirow{2}{*}{ Progression factor } \\
\cline { 2 - 8 } & I & II & III & IV & V & VI & \\
\hline Observed larval body width (mm) + S.E. & $0.69 \pm 0.02$ & $0.85 \pm 0.03$ & $0.91 \pm 0.04$ & $1.18 \pm 0.05$ & $1.38 \pm 0.06$ & $1.65 \pm 0.07$ & \\
\hline Growth ratio & -- & 1.23 & 1.07 & 1.30 & 1.17 & 1.20 & 0.99 \\
\hline Calculated larval body width (mm) & 0.90 & 0.96 & 1.03 & 1.10 & 1.18 & 1.26 & \\
\hline Growth ratio & -- & 1.07 & 1.07 & 1.07 & 1.07 & 1.07 & 0.89 \\
\hline Difference & -0.21 & -0.11 & -0.12 & 0.08 & 0.20 & 0.39 & \\
\hline Per cent difference & -29.97 & -12.89 & -12.82 & 6.91 & 14.84 & 23.79 & \\
\hline
\end{tabular}

\section{Temperature at $30{ }^{\circ} \mathrm{C}$}

The results presented in Table 11 indicated that the larval body width of $C$. cephalonica for I, II, II, IV, V and VI instars reared at $25{ }^{\circ} \mathrm{C}$ temperature was $0.71+0.02,0.88+0.03,0.95+$
$0.04,1.32+0.05,1.45+0.06$ and $1.68+0.07 \mathrm{~mm}$, respectively. The mean observed and calculated progression factors were 0.99 and 0.90 , respectively. The regression equation was $\log _{10} \mathrm{y}=-0.0708+0.0336 \mathrm{x}$.

Table 11: Comparison of observed and calculated values of mean measurements of larval body width (mm) of C. cephalonica at $30{ }^{\circ} \mathrm{C}$ temperature

\begin{tabular}{|c|c|c|c|c|c|c|c|}
\hline \multirow{2}{*}{ Parameter } & \multicolumn{9}{|c|}{ Larval instars } & \multirow{2}{*}{ Progression factor } \\
\cline { 2 - 8 } & I & II & III & IV & V & VI & \\
\hline Observed larval body width $(\mathrm{mm})+$ S.E. & $0.71 \pm 0.02$ & $0.88 \pm 0.03$ & $0.95 \pm 0.04$ & $1.32 \pm 0.05$ & $1.45 \pm 0.06$ & $1.68 \pm 0.07$ & \\
\hline Growth ratio & -- & 1.24 & 1.08 & 1.39 & 1.10 & 1.16 & 0.99 \\
\hline Calculated larval body width (mm) & 0.92 & 0.99 & 1.07 & 1.16 & 1.25 & 1.35 & \\
\hline Growth ratio & -- & 1.08 & 1.08 & 1.08 & 1.08 & 1.08 & 0.90 \\
\hline Difference & -0.21 & -0.11 & -0.12 & 0.16 & 0.20 & 0.33 & \\
\hline Per cent difference & -29.27 & -12.69 & -12.79 & 12.30 & 13.74 & 19.56 & \\
\hline
\end{tabular}

\section{Temperature at $35{ }^{\circ} \mathrm{C}$}

The results presented in Table 12 indicated that the larval body length of $C$. cephalonica for I, II, II, IV, V and VI instars reared at $25{ }^{0} \mathrm{C}$ temperature was $0.67+0.02,0.82+$
$0.03,0.98+0.04,1.16+0.05,1.28+0.06$ and $1.58+0.07 \mathrm{~mm}$, respectively. The mean observed and calculated progression factors were 0.99 and 0.89 , respectively. The regression equation was $\log _{10} \mathrm{y}=-0.0757+0.0265 \mathrm{x}$. 
Table 12: Comparison of observed and calculated values of mean measurements of larval body width (mm) of C. cephalonica at $35^{\circ} \mathrm{C}$ temperature

\begin{tabular}{|c|c|c|c|c|c|c|c|}
\hline \multirow{2}{*}{ Parameter } & \multicolumn{9}{|c|}{ Larval instars } & \multirow{2}{*}{ Progression factor } \\
\cline { 2 - 8 } & I & II & III & IV & V & VI & \\
\hline Observed larval body width (mm) + S.E. & $0.67 \pm 0.02$ & $0.82 \pm 0.03$ & $0.98 \pm 0.04$ & $1.16 \pm 0.05$ & $1.28 \pm 0.06$ & $1.58 \pm 0.07$ & \\
\hline Growth ratio & -- & 1.22 & 1.20 & 1.18 & 1.10 & 1.23 & 0.99 \\
\hline Calculated larval body width (mm) & 0.89 & 0.95 & 1.01 & 1.07 & 1.14 & 1.21 & \\
\hline Growth ratio & -- & 1.06 & 1.06 & 1.06 & 1.06 & 1.06 & 0.89 \\
\hline Difference & -0.22 & -0.13 & -0.03 & 0.09 & 0.14 & 0.37 & \\
\hline Per cent difference & -33.25 & -15.72 & -2.91 & 7.60 & 11.00 & 23.37 & \\
\hline
\end{tabular}

\section{Larval body weight}

Temperature at $20^{\circ} \mathrm{C}$

The results Table 13 indicated that the larvae of $C$. cephalonica when grown at $20{ }^{0} \mathrm{C}$ temperature its body weight was recorded to the tune of $0.98 \pm 0.01,1.80 \pm 0.04$,
$3.65 \pm 0.09 .4 .90 \pm 0.12,6.88 \pm 0.14$ and $9.20 \pm 0.18 \mathrm{mg}$ for $\mathrm{I}$, II, II, IV, V and VI instars, respectively. The mean observed and calculated progression factors were 1.32 and 1.23, respectively. The regression equation was $\log _{10} \mathrm{y}=-0.0339+$ $0.1686 x$.

Table 13: Comparison of observed and calculated values of mean measurements of larval body weight (mg) of C. cephalonicaat $20^{\circ} \mathrm{C}$ temperature

\begin{tabular}{|c|c|c|c|c|c|c|c|}
\hline \multirow{2}{*}{ Parameter } & \multicolumn{9}{|c|}{ Larval instars } & \multirow{2}{*}{ Progression factor } \\
\cline { 2 - 8 } & I & II & III & IV & V & VI & \\
\hline Observed larval body weight (mm) + S.E. & $0.98 \pm 0.01$ & $1.80 \pm 0.04$ & $3.65 \pm 0.09$ & $4.90 \pm 0.12$ & $6.88 \pm 0.14$ & $9.20 \pm 0.18$ & \\
\hline Growth ratio & -- & 1.57 & 1.97 & 1.50 & 2.01 & 1.41 & 1.32 \\
\hline Calculated larval body weight (mm) & 1.34 & 1.98 & 2.92 & 4.31 & 6.35 & 9.36 & \\
\hline Growth ratio & -- & 1.47 & 1.47 & 1.47 & 1.47 & 1.47 & 1.23 \\
\hline Difference & -0.36 & -0.18 & 0.73 & 0.59 & 0.53 & -0.16 & \\
\hline Per cent difference & -37.22 & -10.14 & 19.93 & 12.07 & 7.68 & -1.78 & \\
\hline
\end{tabular}

\section{Temperature at $25^{\circ} \mathrm{C}$}

The results table 14 indicated that the larvae of $C$. cephalonica when grown at $25{ }^{\circ} \mathrm{C}$ temperature its body weight was recorded to the tune of $0.90 \pm 0.01,1.92 \pm 0.04$, $3.88 \pm 0.09,4.92 \pm 0.12,6.93 \pm 0.14$ and $9.96 \pm 0.18 \mathrm{mg}$ for $\mathrm{I}$,
II, II, IV, V and VI instars, respectively. The mean observed and calculated progression factors were 1.38 and 1.24, respectively. The regression equation was $\log _{10} \mathrm{y}=-0.0452+$ $0.1728 x$.

Table 14: Comparison of observed and calculated values of mean measurements of larval body weight (mg) of C. cephalonica at $25^{\circ} \mathrm{C}$ temperature

\begin{tabular}{|c|c|c|c|c|c|c|c|}
\hline \multirow{2}{*}{ Parameter } & \multicolumn{3}{|c|}{ Larval instars } & \multirow{2}{*}{ Progression factor } \\
\cline { 2 - 8 } & I & II & III & IV & V & VI & \\
\hline Observed larval body weight (mm) + S.E. & $0.90 \pm 0.01$ & $1.92 \pm 0.04$ & $3.88 \pm 0.09$ & $4.92 \pm 0.12$ & $6.93 \pm 0.14$ & $9.96 \pm 0.18$ & \\
\hline Growth ratio & -- & 2.13 & 2.02 & 1.27 & 1.41 & 1.44 & \\
\hline Calculated larval body weight (mm) & 1.34 & 2.00 & 2.97 & 4.43 & 6.59 & 9.81 & \\
\hline Growth ratio & -- & 1.49 & 1.49 & 1.49 & 1.49 & 1.49 & \\
\hline Difference & -0.44 & -0.08 & 0.91 & 0.49 & 0.34 & 0.15 & \\
\hline Per cent difference & -49.06 & -4.01 & 23.38 & 10.05 & 4.94 & 1.55 & \\
\hline
\end{tabular}

\section{Temperature at $30{ }^{\circ} \mathrm{C}$}

The results table 15 indicated that the larvae of $C$. cephalonica when grown at $30{ }^{0} \mathrm{C}$ temperature its body weight was recorded to the tune of $0.95 \pm 0.01,2.15 \pm 0.04$, $4.01 \pm 0.09,5.62 \pm 0.12,7.30 \pm 0.14$ and $10.20 \pm 0.18 \mathrm{mg}$ for
I, II, II, IV, V and VI instars, respectively. The mean observed and calculated progression factors were 1.37 and 1.25, respectively. The regression equation was $\log _{10} \mathrm{y}=-0.0323+$ $0.1776 \mathrm{x}$.

Table 15: Comparison of observed and calculated values of mean measurements of larval body weight (mg) of C. cephalonica at $30^{\circ} \mathrm{C}$ temperature

\begin{tabular}{|c|c|c|c|c|c|c|c|}
\hline \multirow{2}{*}{ Parameter } & \multicolumn{9}{|c|}{ Larval instars } & \multirow{2}{*}{ Progression factor } \\
\cline { 2 - 8 } & I & II & III & IV & V & VI & \\
\hline Observed larval body weight $(\mathrm{mm})+$ S.E. & $0.95 \pm 0.01$ & $2.15 \pm 0.04$ & $4.01 \pm 0.09$ & $5.62 \pm 0.12$ & $7.30 \pm 0.14$ & $10.20 \pm 0.18$ & \\
\hline Growth ratio & -- & & 2.26 & 1.87 & 1.40 & 1.30 & 1.37 \\
\hline Calculated larval body weight (mm) & 1.40 & 2.10 & 3.17 & 4.76 & 7.17 & 10.79 & \\
\hline Growth ratio & -- & 1.51 & 1.51 & 1.51 & 1.51 & 1.51 & 1.25 \\
\hline Difference & -0.45 & 0.05 & 0.84 & 0.86 & 0.13 & -0.59 & \\
\hline Per cent difference & -47.07 & 2.19 & 21.07 & 15.24 & 1.78 & -5.80 & \\
\hline
\end{tabular}

\section{Temperature at $35{ }^{\circ} \mathrm{C}$}

The results table 16 indicated that the larvae of $C$. cephalonica when grown at $35{ }^{\circ} \mathrm{C}$ temperature its body weight was recorded to the tune of $0.70 \pm 0.01,2.10 \pm 0.01$, $3.56 \pm 0.01,5.20 \pm 0.01,6.36 \pm 0.01$ and $9.55 \pm 0.01 \mathrm{mg}$ for $\mathrm{I}$, II, II, IV, V and VI instars, respectively. The mean observed 
and calculated progression factors were 1.48 and 1.24, respectively. The regression equation was $\log _{10} \mathrm{y}=-0.0619+$

Table 16: Comparison of observed and calculated values of mean measurements of larval body weight (mg) of C. cephalonica at $35^{\circ} \mathrm{C}$ temperature

\begin{tabular}{|c|c|c|c|c|c|c|c|}
\hline \multirow{2}{*}{ Parameter } & \multicolumn{4}{|c|}{ Larval instars } & \multirow{2}{*}{ Progression factor } \\
\cline { 2 - 8 } & I & II & III & IV & V & VI & \\
\hline Observed larval body weight (mm) + S.E. & $0.70 \pm 0.01$ & $2.10 \pm 0.04$ & $3.56 \pm 0.09$ & $5.20 \pm 0.12$ & $6.36 \pm 0.14$ & $9.55 \pm 0.18$ & \\
\hline Growth ratio & -- & 3.00 & 1.70 & 1.46 & 1.22 & 1.50 & 1.48 \\
\hline Calculated larval body weight (mm) & 1.29 & 1.91 & 2.82 & 4.19 & 6.21 & 9.20 & \\
\hline Growth ratio & -- & 1.48 & 1.48 & 1.48 & 1.48 & 1.48 & 1.24 \\
\hline Difference & -0.59 & 0.19 & 0.74 & 1.01 & 0.15 & 0.35 & \\
\hline
\end{tabular}

The biometrical observations of $C$. cephalonica when grown at different temperature levels indicated that larval head capsule width, body length, width and weight was found to be more when grown at $25{ }^{\circ} \mathrm{C}$ temperature. Osman et al. (1983) ${ }^{[3]}$ studied effect of temperature on size of head capsule of $C$. cephalonica and reported average size of head capsule from $0.195 \mathrm{~mm}$ to $1.299 \mathrm{~mm}$ at $28^{\circ} \mathrm{C}$ in first to sixth instar larvae. They also observed average size of head capsule from 0.177 to $1.210 \mathrm{~mm}$ at $30{ }^{\circ} \mathrm{C}$ and 0.194 to $1.270 \mathrm{~mm}$ at $32{ }^{\circ} \mathrm{C}$ in first to sixth instar larvae. Bhubaneshwari et al. (2013) ${ }^{[1]}$ reported the morphometric measurements of $C$. cephalonica that the mean length and breadth of $1^{\text {st }}, 2^{\text {nd }}, 3^{\text {rd }}, 4^{\text {th }}, 5^{\text {th }}$ and $6^{\text {th }}$ instars larvae were $2.72,3.74,5.63,7.55,9.20,11.21$ and $0.31,0.39$, $0.95,1.16,1.35,1.59 \mathrm{~mm}$, respectively.

\section{References}

1. Bhubaneshwari M, Victoria N, Rita, Singh P, Ranabir. Biology and morphometric of Rice moth, Corcyra cephalonica (Stainton). Annals of Plant Protection Sciences. 2013; 21(1):87-89.

2. Dani A, Sharma N, Sehgal SS. The method of sexing pupae and adult of castor semilooper Achaea janata. Indian J Ent. Res. 1980; 3:186-190.

3. Osman NB, Wright VF, Mills RB. The effect of temperatures on certain aspects of the biology of Corcyra cephalonica (St,). In: Proc. of the Third International Working Conference on Stored Product Entomology. 23 27Aug. 1983. Manhattan, Kansas, U.S.A, 1983.

4. Parameshwar H, Jairao K. Effect of Temperature and Humidity Combinations on incubation and hatching of the rice moth, Corcyra cephalonica (Stainton) Egg (Lepidoptera: Galleriidae) Karnataka J Agric. Sci. 1990; 3(3\&4):195-199.

5. Parmeshwar H, Jairao K. Influence of temperature and relative humidity on larval development and survival of the rice moth $C$. cephalonica (Stainton). Madras Agric. J. 1985; 72(5):280-283.

6. Shrivastava RP, Pande YD. Bionomics of the castor semilooper in Rajasthan. Ann. Arid Zone. 1966; 5:262264. 